\title{
Crystallization and Characterization of a New Fluorescent Molecule Based on Schiff Base
}

\author{
Dehua Zhang ${ }^{1^{*}}$, Xiaoyan Zhang² \\ ${ }^{1}$ Department of Chemistry and Environmental Engineering, Hubei Normal University, Huangshi, China; ${ }^{2}$ School of Mathematics and \\ Physics, Huangshi Institute of Tecnology, Huangshi, China. \\ Email: ${ }^{*}$ zhangdehua200@163.com
}

Received November $8^{\text {th }}, 2012$; revised December $20^{\text {th }}, 2012$; accepted December $29^{\text {th }}, 2012$

\begin{abstract}
In this analysis, the single crystal of schiff base has been synthesized and the purity of material has been increased by repeated recrystallization process. Single crystal was grown by adopting the method growing in a slow evaporation solution using ethanol as solvent at room temperature. A new fluorescent molecule based on Schiff base has been synthesised and its binding properties investigated by fluorescence spectroscopy to show that it can selectively bind $\mathrm{Cu}^{2+}$ with fluorescence quenching.
\end{abstract}

Keywords: Slow Evaporation; X-Ray Diffraction; Schiff Base; Fluorescence Quenching; $\mathrm{Cu}^{2+}$

\section{Introduction}

Because of structural flexibility and their application for switching materials and so on, Schiff base compounds are one of the most extensively used ligands in the field of coordination chemistry [1]. During the past decades, Schiff bases have been intensively studied due to their strong coordination capability as well as their diverse biological activities, such as antibacterial, antitumor, etc. [2]. Schiff bases have received much attention because of their potential applications with some of these compounds exhibiting various pharmacological activities, as noted by their anticancer [3], anti-HIV [4], antibacterial and antifungal properties. In addition, some of them may be used as analytical reagents for the determination of trace elements [5], Schiff-bases can readily form stable complexes with most transition metals, in which some may exhibit interesting properties, we have determined the crystal structure of the title compound.

In previous work, we have reported the synthesis and developed their function as selective fluorescent chemsensors for $\mathrm{Cu}^{2+}[6]$. In continuing our research to develop new fluorescent chemsensors based on Schiff base, we have designed a new molecule of 1 which have big $\pi$-systems that can be used as the signaling subunit in their two sidewalls and two oxygen atoms of ring and two $\mathrm{C}=\mathrm{N}$ atoms in their structure be used as the potential binding sites. We now report their synthesis and a binding study with different metal ions.

\footnotetext{
*Corresponding author.
}

\section{Experimental Details}

Preparation of 1 [6-8]: To a solution of 2-oxo-2H-chromene-3-carbohydrazide $(0.3 \mathrm{~g}, 1.5 \mathrm{mmol})$ in ethanol (20 $\mathrm{ml}$ ) was added 2-hydroxybenzaldehyde $(0.3 \mathrm{ml}, 3 \mathrm{mmol})$. The reaction mixture was stirred for about $5 \mathrm{~h}$. Subsequently, it was cooled to room temperature. The resultant orange solution was filtered. Yellow precipitate obtained was dissolved in ethanol $(1.5 \mathrm{~g}, 31.8 \%)$. The synthesis of the shciff base molecules 1 is re presented in the following equation :

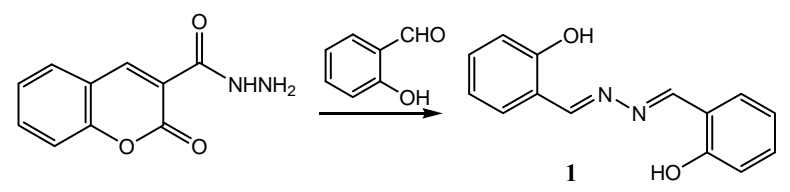

Yellow crystals suitable for XRD formed after a few days of slow evaporation of the solvent at room temperature over several days. Yellow single crystals of the title compound is shown in Figure 1. The crystal structures of 1 clearly revealed that it has well-defined geometry due to the rigidity that the fused rings confer on the molecule.

\section{Characterization}

All reagents obtained from commercial sources were of analyzed grade. Melting points were determined with XT4A micromelting point apparatus and were uncorrected. The $1 \mathrm{H}$ NMR was recorded on a Mercury Plus-400 


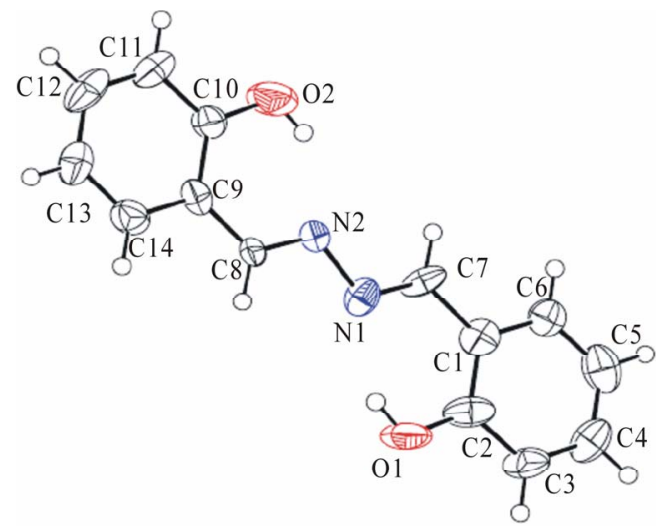

Figure 1. The single crystals.

spectrometer with TMS as internal reference and $\mathrm{CDCl}_{3}$ as solvent. IR were recorded on a Perkin-Elmer PE-983 IR spectrometer as $\mathrm{KBr}$ pellets with absorption in $\mathrm{cm}^{-1}$. MS were obtained with Finnigan Trace MS instrument using EI method. Elemental analyses were carried out on a Vario EL III instrument. Fluorescence spectra were determined on a Hitachi F-4500.

\section{Results and Discussion}

\subsection{Single Crystal X-Ray Diffraction Analysis}

Single crystal X-ray diffraction studies were carried out on the grown crystals. The X-ray date were collected using X-ray diffractometer (Model: Bruker Smart APEX$\mathrm{CCD}$ ). The observed results indicate that the crystal belongs to triclinic crystal system and the determined unit cell parameters are $a=17.505$ (5) $\AA, b=6.3135$ (18) $\AA$, $c=16.578(5) \AA, \alpha=90^{\circ}, \beta=97.255(5)^{\circ}, \gamma=90^{\circ}$ and $V$
$=1817.5(9) \AA^{3}$.

\subsection{The Structure Characterized}

Compound of 1. M.p. $145.2^{\circ} \mathrm{C}-147.8^{\circ} \mathrm{C}$ (dec.). ( $\mathrm{KBr}$, $\left.\mathrm{cm}^{-1}\right): 3620,1645,1600,1503,1445.1 \mathrm{H} \mathrm{NMR} \delta: 5.2(\mathrm{~s}$, 2H, OH), 6.8 (d, 4H, PhH), 7.2 (q, 2H, PhH), 7.6 (d, 2H, $\mathrm{PhH}), 8.8$ (s, 2H, $\left.\mathrm{CO}_{2} \mathrm{CH}_{2} \mathrm{CH}_{3}\right), 7.26$ - 7.45 (m, 4H, $\left.\mathrm{ArH}\right)$. MS (EI): $\mathrm{m} / \mathrm{z}=241[\mathrm{M}+\mathrm{H}]+$ Anal. Calcd for $\mathrm{C}_{14} \mathrm{H}_{12} \mathrm{~N}_{2} \mathrm{O}_{2}$ (240.26): C, 69.99; H, 5.03; N, 11.66; O, 13.32, Found: C, 69.67; H, 5.33; N, 11.57; O, 13.53.

\subsection{Fluorescent Spectroscopy}

The binding properties of the Schiff base with various metal ions were investigated by fluorescent spectroscopy titration experiments. Changes of the fluorescence properties of Schiff base $\left(2 \times 10^{-5} \mathrm{M}\right.$ in acetonitrile $)$ solution caused by 15 equiv. of various metal ions $\left(\mathrm{Co}^{2+}, \mathrm{Cr}^{3+}\right.$, $\mathrm{Sn}^{4+}, \mathrm{Cu}^{2+}, \mathrm{Sr}^{2+}, \mathrm{Ag}^{+}, \mathrm{Ni}^{2+}, \mathrm{Pb}^{2+}, \mathrm{Fe}^{3+}$ ) were measured until their emission intensity were constant.

The result showed that $\mathrm{Cu}^{2+}$ produced significant quenching in their fluorescent emission. The other metal ions that were tested only show a relatively insignificant change (Figure 2). It can be concluded that 1 has a higher selectivity for the recognition of $\mathrm{Cu}^{2+}$.

The sensitivity of the fluorescence emission response of 1 towards $\mathrm{Cu}^{2+}$ was also examined under the same conditions with various $\mathrm{Cu}^{2+}$ concentrations (Figure 3). The fluorescence intensity of 1 decreased continually upon addition of $\mathrm{Cu}^{2+}$. When the concentration of $\mathrm{Cu}^{2+}$ increased to 15 equiv, the fluorescence intensity of 1 was

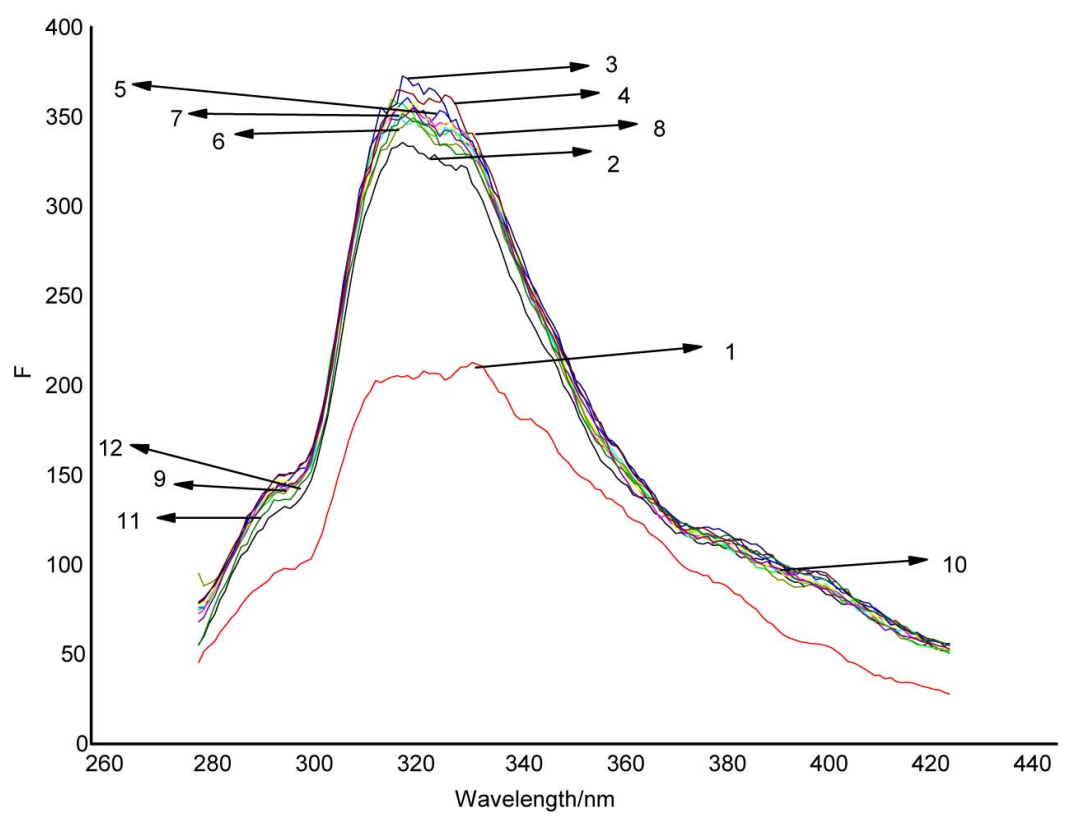

Figure 2. Fluorescence emission changes of $4\left(1 \times 10^{-5} \mathrm{M}\right)$ in acetonitrile in the presence of $2 \times 10^{-4}$ various metal ions (excitation at $320 \mathrm{~nm}$ ). (1) $\mathrm{Cu}^{2+}$, (2) host, (3) $\mathrm{Sn}^{4+}$, (4) $\mathrm{Fe}^{3+}$, (5) $\mathrm{Sr}^{2+}$, (6) $\mathrm{Ag}^{+}$, (7) $\mathrm{Ni}^{2+}$, (8) $\mathrm{Cr}^{3+}$, (9) $\mathrm{Co}^{2+}$, (10) $\mathrm{Pb}^{2+}$. 


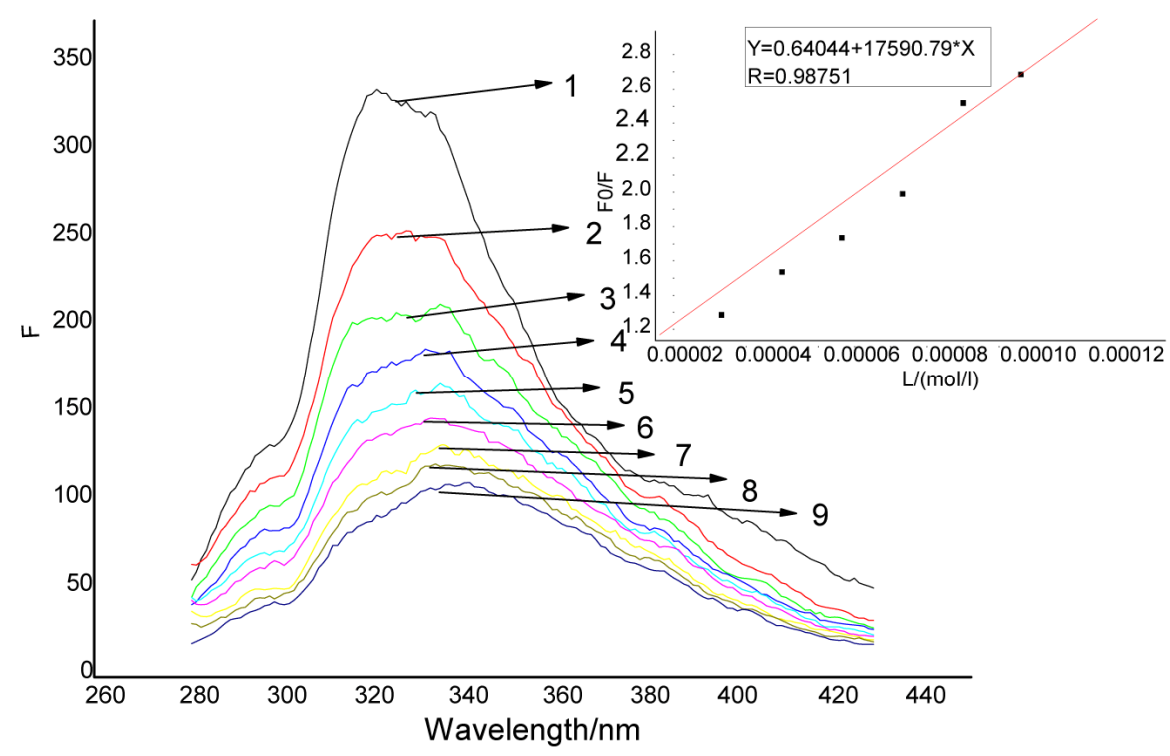

Figure 3. Fluorescence emission spectra (excitation at $320 \mathrm{~nm})$ of $1\left(1 \times 10^{-5} \mathrm{M}\right)$ in DMF in the presence of different concentration of $\mathrm{Cu}^{2+}$. Inset: Stern-Volmer plot of the emission data.

reduced to $80 \%$ of the initial value. From a Stern-Volmer plot (Figure 3), the quenching constants were estimated $1.75 \times 10^{4} \mathrm{M}^{-1}$.

\section{Conclusion}

A new Schiff base molecule as fluorescent chemosensor has been designed and synthesized. They display high selectivity for $\mathrm{Cu}^{2+}$ revealed by fluorescence quenching. In future work, our efforts will be focused on the elucidation of the detailed mechanisms of these fluorescent chemosensor.

\section{Acknowledgements}

We thank the Hubei provincial Department of Education (Grant No.D20112503) for financial support.

\section{REFERENCES}

[1] S. Yamada, "Advancement in Stereochemical Aspects of Schiff Base Metal Complexes," Coordination Chemistry Reviews, Vol. 190-192, 1999, pp. 537-555. doi:10.1016/S0010-8545(99)00099-5

[2] S. Koizumi, M. Nihei, M. Nakano and H. Oshio, "Antiferromagnetic FeIII $_{6}$ Ring and Single-Molecule Magnet $\mathrm{MnII}_{3} \mathrm{MnIII}_{4}$ Wheel," Inorganic Chemistry, Vol. 44, No. 5, 2005, pp. 1208-1210. doi:10.1021/ic0484203

[3] V. T. Dao, C. Gaspard, M. Mayer, G. H. Werner, S. N.
Nguyen and R. J. Michelot, "Synthesis and Cytotoxicity of Gossypol Related Compounds," European Journal of Medicinal Chemistry, Vol. 35, No. 9, 2000, pp. 805-813. doi:10.1016/S0223-5234(00)00165-3

[4] D. Sriram, P. Yogeeswari, N. S. Myneedu and V. Saraswat, "Abacavir Prodrugs: Microwave-Assisted Synthesis and Their Evaluation of Anti-HIV Activities," Bioorganic \& Medicinal Chemistry Letters, Vol. 16, No. 8, 2006, pp. 2127-2129. doi:10.1016/j.bmcl.2006.01.050

[5] A. Soliman and W. Linert, "Structural Features of ONSDonor Salicylidene Schiff Base Complexes," Monatsheftefur Chemie Chemical Monthly, Vol. 138, No. 3, 2007, pp. 175-189.

[6] A. Giuseppe, C. Annalinda, L. Elisa and S. Domenico, "Synthesis, Characterization of a Novel Calixarene Having Dipyridyl Pendants and Study of Its Complexes with $\mathrm{Cu}^{2+}$ and $\mathrm{Co}^{2+}$," Tetrahedron Letters, Vol. 44, No. 29, 2003, pp. 5415-5418. doi:10.1016/S0040-4039(03)01319-4

[7] Z. Dehua, "Synthesis and Binding Properties of a New Fluorescent Molecular Clip Based on 2-Ethyl Cyanoacrylate," Journal of Chemical Research, Vol. 34, 2010, pp. 635-636.

[8] E. E. Naser, G. T. Siang, S. Y. Chin and A. Rohana, "6,6'-Di-tert-butyl-2,2'-[1,2-phenylenebis(nitrilomethylid yne)]diphenol," Acta Crystallographica, Vol. E65, 2009, pp. o3142-o3143. 